\title{
ANALISIS DYNAMIC GOVERNANCE PADA PROGRAM LAYANAN LAYAD RAWAT DI DINAS KESEHATAN KOTA BANDUNG
}

\section{ANALYSIS DYNAMIC GOVERNANCE ON THE LAYAD RAWAT PROGRAMME IN BANDUNG CITY HEALTH OFFICE}

\author{
Alifatu Lela Mazidah, Feni Astuti, Muhamad Febi Romdhoni, Muhamad Ichsana \\ Nur, Tedi Juana \\ Fakultas Ilmu Sosial dan Ilmu Politik, \\ Universitas Islam Negeri Sunan Gunung Djati Bandung \\ Alifaelmazidah17@gmail.com
}

\begin{abstract}
Abstrak
Sebagai salah satu kota sehat di Jawa Barat, pemerintah Kota Bandung telah berkomitmen untuk tetap mengembangkan layanan publik yang lebih baik dalam perawatan kesehatan. Salah satu upaya yang telah dilakukan untuk mendukung visi itu adalah melalui program "Layad Rawat". Meskipun demikian, potensi Bandung sebagai kota sehat sebenarnya jauh lebih baik dibandingkan dengan yang telah disadari. Aktualisasi ideal dari potensi-potensi ini telah terhambat sebagai akibat dari kenyataan bahwa pemerintah belum menyediakan sumber perawatan kesehatan yang memadai dalam hal melayani masyarakat. Penelitian ini bertujuan untuk menganalisis tata kelola dinamis pada program "Layad Rawat" di Dinas Kesehatan Kota Bandung. Penelitian ini adalah penelitian deskriptif dengan menggunakan pendekatan kualitatif. Data penelitian dikumpulkan dengan wawancara mendalam dan studi literatur. Hasil penelitian ini menunjukkan bahwa program "Layad Rawat" mampu merefleksikan teori tata kelola yang dinamis meskipun belum ada perbaikan serius terkait dengan aturan dan regulasi yang cenderung lebih fleksibel.
\end{abstract}

kata kunci: Dynamic Governance, pelayanan publik, layanan layad rawat, kota bandung

\begin{abstract}
As the one of the healthful cities in West Java, the government of Bandung City has been commited to develop a better public service in a health care. One of the endeavors that has been made to support that vision is through "Layad Rawat" programme. Nonetheless, the potentials of Bandung as the healthful city could be in fact much better in contrast to what has been realized. The ideal actualization of these potentials has been obstructed in consequence of the reality that the government has yet to provide adequate sources of health care in terms of serving the society. The research aims to analyze the dynamic governance on "Layad
\end{abstract}


Rawat" programme in Bandung City Health Office. This research is a descriptive research utilizing the qualitatif approach. The research data was collected by indepth interviews and literature study. The result of this research shows that "Layad Rawat" programme is capable of reflecting the theory of dynamic governance despite of there has been no serious improvement associated with any rules and regulations which tend to be more flexible.

keywords: dynamic governance, public service, layad rawat programme, bandung city.

\section{A. Pendahuluan}

Dynamic governance dapat dikatakan sebagai pemerintahan yang dinamis. Artinya, pemerintah dapat menyesuaikan kebijakan yang dibuat sesuai dengan kebutuhan masyarakat juga mengikuti perkembangan zaman. Pola penyelenggaraan pemerintah dengan konsep dynamic governance menuntut pemerintah untuk memiliki kapabilitas seperti berfikir jauh ke depan (thinking ahead), berfikir kembali (thinking again), dan berfikir secara terbuka seperti belajar dari negara lain (thinking across). Oleh karena itu, konsep pemerintahan yang dinamis dapat diterapkan di berbagai bidang pelayanan yang dilakukan pemerintah, termasuk di bidang pelayanan kesehatan.

Dikutip dalam teks pidato Ridwan Kamil pada acara Launching Mobil Ambulance Mini ICU dan Motor Ambulance tahun 2017, yang mengatakan bahwa Indonesia termasuk Kota Bandung kini sedang mengalami pola perubahan penyakit. Hal tersebut ditandai dengan meningkatnya kematian dan kesakitan akibat penyakit tidak menular seperti Stroke, Jantung, dan lain sebagainya.

Hal tersebut menjadi beban pemerintah maupun masyarakat, sebab biaya pengobatan untuk penyakit tidak menular memerlukan biaya yang cukup besar juga teknologi yang canggih. Keterbatasan ekonomi menjadi salah satu penyebab masyarakat tidak mendapatkan pengobatan secara maksimal. Kondisi fisik pasien seperti lansia yang mengalami stroke dan sulinya transportasi juga menjadi hambatan dalam melakukan pengobatan.

Data menunjukkan bahwa pada tahun 2017 jumlah penduduk yang sakit mencapai 973.998 jiwa. Hal tersebut menunjukkan adanya indikasi pola perubahan penyakit yang cukup tinggi. Oleh karena itu jika ditinjau berdasarkan konsep dynamic governance,maka pemerintah dituntut untuk dapat menyesuaikan kebijakan untuk menjawab permasalahan tersebut. 
Untuk menjawab tantangan tersebut, pemerintah Kota Bandung khususnya Dinas Kesehatan Kota Bandung membuat suatu inovasi program yang dinamakan dengan Layanan Layad Rawat. Program tersebut dikukuhkan oleh Peraturan Walikota Bandung Nomor 703 Tahun 2017 tentang Layanan Layad Rawat dan Keputusan Walikota Nomor 440/KEP.704 DINKES/TAHUN 2017 Tentang Penetapan Standar Operasional Prosedur Pengesahan Layanan Layad Rawat.

Dalam prakteknya, Layanan Layad Rawat ini telah menerima beberapa penghargaan. Seperti dalam acara Inovation Award 2018 yang diadakan oleh Indonesia Health Care Forum (IHCF), Layanan Layad Rawat ini menerima penghargaan dalam kategori Sistem Penanggulangan Gawat Darurat Terpadu (SPGDT). Namun meskipun demikian, setelah peneliti melakukan observasi terkait Layanan Layad Rawat ini peneliti menemukan beberapa kekurangan yang menjadikan program tersebut belum sesuai dengan konsep dynamic governance. Maka peneliti tertarik untuk mengetahui bagaimana implementasi konsep dynamic governance khususnya dilihat dalam indikator thinking ahead pada Layanan Layad Rawat di Dinas Kesehatan Kota Bandung.
Dalam penelitian ini, peneliti menggunakan teori Dynamic Governance yang dikemukan oleh Neo and Chen. Neo dan Chen (Boon \& Geraldin, 2007) mengemukakan bahwa Dynamic governance adalah "Dynamic Governance is the ability of a governance to continually adjust it is public policies and programs as well as change the way they are formulated and implemented, so that the long-term interests of the nation are achieved".

Menurut Neo dan Chen, pada dasarnya konsep dynamic governance tertuju pada perubahan yang hanya menekankan pada dua kunci penting, yaitu Capalities dan Culture. Oleh karena itu, Neo dan Chen merumuskan kerangka pemikiran sederhana yang mengacu pada terbentuknya konsep dynamic governance sebagai berikut:

Gambar 1.1

Kerangka Pemikiran Dynamic Governance

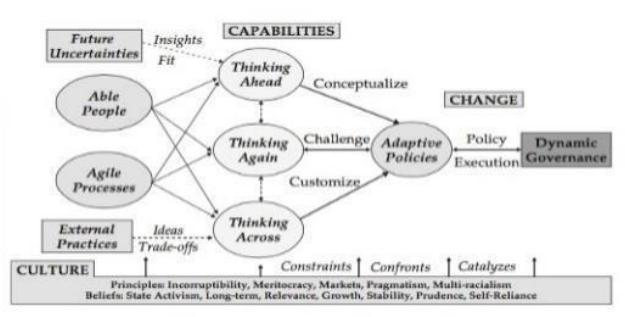

(sumber: Neo and Chen,2007: 13) A. Capabilities 


\section{B. Metode Penelitian}

Penelitian ini merupakan penelitian deskriptif dengan menggunakan pendekatan kualitatif, yang bertujuan untuk memahami bagaimana penerapan dan proses terbentuknya dynamic governance dalam penyelenggaraan Layanan Layad Rawat. Penelitian ini dilakukan di Dinas Kesehatan Kota Bandung. Teknik pengumpulan data dilakukan melalui wawancara, studi pustaka, dan dokumentasi. Sedangkan narasumber dari penelitian ini adalah pejabat Dinas Kesehatan Kota Bandung sebagai koordinator pusat, Ketua Call Center 119 sebagai koordinator pelaksana teknis, petugas Layanan Layad Rawat Puskesmas sebagai pelaksana teknis, dan masyarakat sebagai pengguna. Teknik analisis data yang digunakan adalah Data Condensation, Display Data, dan Conclusion Drawing. Sedangkan pemeriksaan keabsahan dilakukan dengan teknik triangulasi data.

\section{Pembahasan}

Berdasarkan hasil observasi yang dilakukan oleh peneliti, penerapan konsep dynamic governance dapat dilihat pada uraian berikut:
A. Capability
1) Thinking Ahead

Pada kemampuan thinking ahead, peneliti melihat dari beberapa faktor sebagai berikut :

a. Mental Preparedness

Prediksi mengenai adanya tuntutan zaman globalisasi yang berkembang semakin cepat dan teknologi yang semakin canggih menjadi latar belakang adanya pembaharuan atau inovasi dari sebuah program Call Center 119 menjadi program Layanan Layad Rawat. Program tersebut bertujuan untuk memudahkan masyarakat dalam mengakses layanan kesehatan dengan hanya menggunakan media telepon.

Selain itu, peneliti juga melihat dari kesiapan awal dari Dinas Keshehatan Kota Bandung. Yakni adanya sosialisasi awal sebelum program tersebut launching. Sosialisasi tersebut dilakukan dengan mengundang perwakilan wilayah yang meliputi kelurahan, kecamatan, dan puskesmas di Kota Bandung. Sosialisasi tersebut diadakan untuk memberikan arahan terkait program Layanan Layad Rawat agar ketika launching program tersebut berjalan sesuai dengan apa yang diharapkan.

Namun, setelah program tersebut launching, tidak ada tinjauan lebih lanjut yang dilakukan oleh Dinas Kesehatan terkait sosialisasi yang dilakukan. Sebab banyak masyarakat yang tidak mengetahui adanya program Layanan Layad Rawat 
tersebut. Hal tesebut dibuktikan dengan adanya beberapa puskesmas yang salah satunya adalah UPT Puskesmas Cibiru, sosialisasi hanya dilakukan pada saat imunisasi saja. Tidak ada waktu khusus yang digunakan untuk sosialisasi programnya. Sedangkan dalam kegiatan imunisasi tersebut tidak semua masyakat terlibat. Sehingga perlu diadakan tinjauan lebih lanjut terkait sosialisasi yang dilakukan.

Untuk memantapkan mental preparedness dalam melakukan pelayanan publik kepada masyarakat, maka Dinas Kesehatan Kota Bandung melakukan benchmarking dengan Dinas Kesehatan yang berada di Kota Makasar. Yang dimana untuk memaksimalkan pelayanan kesehatannya Dinkes Makasar ini memiliki mobil yang siap sedia untuk memberikan pelayanan kesehatan kepada masyarakat. Sedangkan untuk Dinkes Kota Bandung, mengingat Pusat Teknis Layanan Layad Rawat berada di pusat kota, maka disediakanlah Motor Ambulance dan mobil mini ICU dengan fasilitas yang cukup lengkap. Sehingga dengan adanya dua jenis kendaraan tersebut diharapkan dapat lebih mengefisienkn waktu dalam hal pemberian pelayanan kepada masyarakat.

\section{b. flexibility}

Untuk mengetahui fleksibilitas dari layanan layad rawat, maka peneliti menilai dari Standar Operasional Prosedur layanan layad rawat. Setelah dilakukan observasi, peneliti menemukan bahwa pemberian layanan layad rawat ini dinilai belum mencapai tingkat fleksibel, dikarenakan pasien yang ingin menggunakan layanan layad rawat tersebut harus melalui proses yang cukup panjang.

Gambar berikut menunjukkan tahapan yang harus dilalui untuk mendapatkan layanan layad rawat yang sesuai dengan Keputusan Walikota Bandung Nomor 440/Kep. 704-Dinkes/2017 tentang Penetapan Standar Operasional Procedur :

Gambar 1.2

Proses Pemberian Layanan Layad Rawat

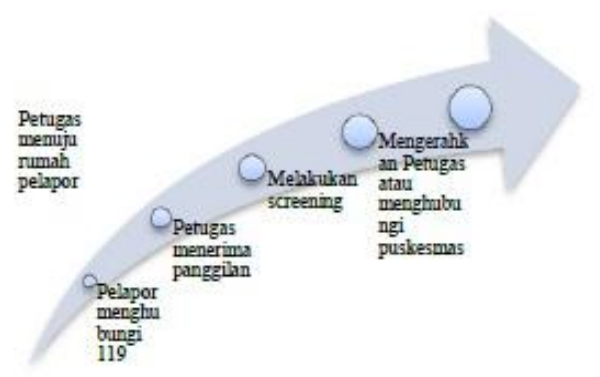

(sumber: Perwal No. 703 tahun 2017 tentang Standar Operasional Procedure Layanan Layad Rawat *diolah peneliti) 
Gambar tersebut menunjukkan bahwa alur dari layanan layad rawat cukup panjang, ditambah dengan posisi PCS 119 yang berada di pusat kota sehingga membuat petugas layad rawat seringkali mengalami hambatan seperti kemacetan. Sedangkan, untuk menangani pasien dengan kasus level 1 dan level 2 yaitu kasus gawat darurat tidak terencana, petugas dituntut untuk sampai ke rumah pasien maksimal 30 menit. Hal tersebut tentu menjadi hambatan yang cukup serius, karena pasien dengan level 1 dan level 2 ini memerlukan penanganan segera.

Melihat adanya proses yang cukup panjang tersebut, peneliti mencoba untuk melakukan observasi terhadap masyarakat. Hasil observasi menunjukkan bahwa dilihat dari proses untuk mendapatkan layanan layad rawat tersebut, masyarakat lebih tertarik unuk datang langsung ke puskesmas, rumah sakit, ataupun melalui kader-kader yang menghubungi langsung ke puskesmas.

Hal tersebut diperkuat dengan adanya data yang menunjukkan adanya kenaikan pada jumlah pengunjung puskesmas dari tahun 2016 sampai dengan tahun 2017. Pada tahun 2016, jumlah pengunjung puskesmas sebanyak 1.815.540 jiwa. Pada tahun 2017, jumlah pengunjung puskesmas bertambah menjadi
2.153.380 jiwa. Sedangkan pada layanan layad rawat pada tahun 2017 terdapat 180 kasus yang ditangani. Hingga sepanjang tahun 2017, jumlah pengguna layanan layad rawat cenderung tidak stabil dan menurun. Berdasarkan wawancara yang dilakukan dengan ibu sri, selaku pejabat di Dinas Kesehatan Kota Bandung menyatakan bahwa pengguna layanan layad rawat terbanyak adalah masyarakat daerah Kopo. Karena, posisi markas besar layanan layad rawat dekat dengan Kopo.

Adapun fleksibilitas dapat dilihat dari kapasitas Sumber Daya Manusia dan sarana prasarana yang dimiliki. Tabel berikut menunjukkan jumlah SDM dan sarana prasana yang dimiliki:

Gambar 1.3

Jumlah Sumber Daya Manusia

\begin{tabular}{|c|l|c|}
\hline NO & \multicolumn{1}{|c|}{ SDM } & JUMLAH \\
\hline 1 & Dokter & 3 Orang \\
\hline 2 & perawat & 33 Orang \\
\hline 3 & $\begin{array}{l}\text { Operator Call } \\
\text { Center }\end{array}$ & 15 Orang \\
\hline 4 & Driver & 350 Orang \\
\hline 5 & Relawan & 418 Orang \\
\hline & jumlah & \\
\hline
\end{tabular}


Gambar 1.4

Jumlah Sarana dan Prasarana

\begin{tabular}{|c|c|c|}
\hline NO & $\begin{array}{c}\text { SARANA } \\
\text { PRASARANA }\end{array}$ & JUMLAH \\
\hline 1 & Mobil Ambulance & 10 Unit \\
\hline 2 & Motor Ambulance & 4 unit \\
\hline & Jumlah & 14 unit \\
\hline
\end{tabular}

(sumber: PPT PCS 119)

Dalam tabel tersebut dapat dilihat bahwa jumlah Sumber Daya Manusia dan sarana prasarana di UPT Pusat Pelayanan Keselamatan Terpadu (Call center 110) sudah sangat memadai. Pak Eka selaku Kepala PCS 119 menyatakan bahwa jumlah sarana dan prasarana yang dimiliki saat ini menjadi point penting untuk selalu meningkatkan pelayanan kepada masyarakat. Dalam memberikan layanan tersebut, PCS 119 juga tetap meningkatkan modernitas dari peralatan yang ada. Maka dilihat dari jumlah SDM dan sarana prasarananya, peneliti menilai hal tersebut sudah mencapai tingkat fleksibilitas.

\section{c. Openness}

Pada indikator Openness ini peneliti menilai dari sikap Dinas Kesehatan yang memberikan layanan tersebut kepada siapa saja, meskipun ia bukan warga asli Kota Bandung dan tidak memiliki KTP Kota Bandung. Selama pasien berada dalam radius Kota Bandung, maka ia berhak untuk mendapatkan pelayanan sebagaimana mestinya.
Peneliti juga menilai dari sikap keterbukaan Dinas Kesehatan yang memberikan pelayanan tanpa adanya sikap pilih kasih. Hal tersebut dapat dilihat dari persyaratan bagi seseorang yang berhak untuk mendapatkan layanan seperti berikut ini:

1) Adanya keterbatasan fisik pasien. Seperti pasien yang menderita stroke, dll.

2) Keterbatasan ekonomi

3) Keterbatasan akses seperti transportasi.

Selain itu, adanya dukungan dari para Stakeholder juga merupakan salah satu indikasi yang menunjukkan tercapainya indikator openness pada layanan layad rawat tersebut. Berdasarkan hasil observasi menunjukkan bahwa dukungan para stakeholder sangat baik. Bahkan pada layanan ini telah bekerjasama dengan beberapa intansi kesehatan maupun diluar intansi kesehatan seperti Diskominfo dan kepolisian.

Namun meskipun demikan, terdapat perbedaan pendapat antara Dinkes Kota Bandung dengan PCS 119 mengenai rencana diadakannya aplikasi layad rawat yang dibuat layaknya aplikasi ojeg online. Yang dapat memudahkan masyarakat untuk memantau keberadaan petugas layad rawat dan memudahkan petugas untuk mengetahui posisi dari pasien yang memerlukan layanan layad rawat tersebut. 
Perbedaan pendapat terletak pada Dinas Kesehatan yang menolak adanya aplikasi tersebut, karena dengan menggunakan aplikasi layaknya ojeg online mengharuskan masyarakat untuk mendownload dan pada akhirnya akan berbayar. Sedangkan pihak PCS 119 menyetujui adanya aplikasi tersebut karena akan memudahkan masyarakat maupun petugas.

Hal tersebut menunjukkan adanya sikap kurang terbuka antar Dinkes Kota Bandung dengan PCS 119. Harus ada pembicaraan lebih lanjut terkait aplikasi tersebut. Dan adanya kesalahpahaman bahwa dengan adanya aplikasi tersebut layanan akan berbayar. Padahal, dari pihak

PCS 119 menyatakan bahwa dengan adanya aplikasi itupun tidak akan menjadi berbayar.

\section{B. Culture}

Culture merupakan budaya organisasi yang diterapkan dalam suatu organisasi. Peneliti melihat culture Dinkes Kota Bandung dari aspek prinsip yang dijalankan oleh Dinkes Kota Bandung. Berdasarkan Perwal No. 704 tahun 2017, pada Bab 1 Bagian ke empat Pasal 5 menjelaskan bahwa progam Layanan Layad Rawat harus dilaksanakan secara komperehensif serta berkesinambungan. Maka peneliti dapat menilai culture Dinkes Kota
Bandung melalui beberapa aspek berikut ini:

a) promotif

promotif yang dimaksud adalah Dinkes Kota Bandung melaksanakan penyuluhan berupa promosi kesehatan kepada masyarakat. Penyuluhan yang dilaksanakan oleh Dinkes Kota Bandung terkait program Layanan Layad Rawat dilakukan oleh pelaksana medis dasar. Yang dalam hal ini adalah UPT Puskesmas di Kota Bandung.

Dinkes Kota Bandung selaku koordinator teknis layanan layad rawat melakukan sosialiasi awal kepada para stakeholder sebelum program tersebut launching. Sedangkan sosialisasi selanjutnya dilakukan Dinkes dalam acaraacara tertentu dengan cara menyisipkan berbagai penjelasan mengenai program Layanan Layad Rawat.

b) preventif

preventif dapat diartikan sebagai kegiatan pencegahan yang dilakukan oleh Dinkes Kota Bandung. Kegiatan pencegahan tersebut dilakukan untuk meminimalisir pertumbuhan penyakit yang ada pada masyarakat di Kota Bandung. Kegiatan pencegahan yang dilakukan oleh Dinkes berupa pembinaan keluarga rawan kepada setiap UPT Puskesmas di Kota Bandung yang kemudian disosialisasikan kembali kepada masyarakat. 
Pembinaan keluarga rawan bertujuan untuk memberikan edukasi kesehatan dan pembinaan mengenai kesehatan keluarga. Hal tersebut telah dilakukan di setiap UPT Puskesmas di Kota Bandung. Berikut ini merupakan laporan pembinaan keluarga rawan di UPT Puskesmas Cibiru:

Gambar 1.5

Pembinaan keluarga rawan tahun

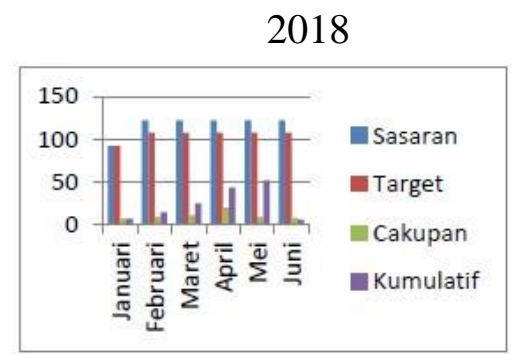

c) kuratif

kuratif merupakan bentuk penyembuhn yang dilaksanakan oleh Dinkes Kota Bandung. Hal tersebut dibuktikan dengan adanya berbagai inovasi pelayanana kesehatan berupa program seperti Layanan Layad Rawat, Kekasih Juara, dan lain sebagainya. Program penyembuhan yang dilakukan oleh Dinkes Kota Bandung dapat dikatakan berhasil.

Dengan adanya beberapa inovasi pelayanan kesehatan tersebut bertujuan untuk memberikan fasilitas kesehatan kepada masyarakat berupa pemberian perawatan untuk menunjang penyembuhan pasien.

\section{d) rehabilitatif}

rehabilitatif adalah prinsip Dinkes dalam melayani kesehatan untuk pemulihan pasien di Kota
Bandung. Rehabilitatif dapat dilihat dari terlaksananya program Layanan Layad Rawat di UPT Puskesmas mengunjungi pasien secara teratur dalam rangka untuk memberikan upaya pemulihan pada pasien tersebut.

\section{Penutup}

a) Simpulan

Berdasarkan hasil analisis yang peneliti lakukan, program Layanan Layad Rawat sudah sesua dengan konsep Dynamic Governance. Karena program ini diadakan untuk menjawab tantangan dengan menyesuakan program atau kebijakan dengan perkembangan zaman yang menuntut adanya kecepat tanggapan. Meskipun dalam pelaksanaannya terdapat beberapa kendala, tetap hingga saat ini Dinas Kesehatan Kota Bandung terus melakukan pembaharuan melalui kegiatan evaluasi yang dilakukan setiap tahunnya.

b) Rekomendasi

Berdasarkan penelitian yang dilakukan, maka peneliti memberikan beberapa rekomendasi sebagai berikut:

1. Diadakannya monitoring sejauh mana sosialisasi dilakukan sesuai dengan Peraturan Walikota Nomor 703 tahun 2017 tentang Layanan Layad Rawat, seperti yang tercantum dalam BAB IX Pasal 22 Ayat (3) tentang Pembinaan dan 
Pengawasan terhadap

Pelaksanaan Program Layanan

Layad Rawat, karena pengetahuan danminat masyarakat Kota Bandung terhadap program ini merupakan salah satu hal yang terpenting untuk keberhasilan program.

2. Aplikasi Layad Rawat sebaiknya memang harus dibuat agar lebih fleksibel untuk memudahkan masyarakat dalam memantau keberadaan petugas Layad Rawat yang hendak menuju rumah pasien. Kejelasan terkait besaran tarif pelayanan yang dibebankan kepada masyarakat sebaiknya dicantumkan di dalam aplikasi, karena tidak semua masyarakat mengetahui tentang besaran tarif yang tercantum dalam Peraturan Daerah Kota Bandung No 3 Tahun 2010.

3. Diadakan penjelasan lebih lanjut mengenai program Perkesmas dan Layad Rawat terencana khususnya mengenai pelaporan dari program Perkesmas dengan Program Layad Rawat.

\section{Daftar Pustaka}

Asmawi Rewansyah. 2011. Kepemimpinan Dalam Pelayanan Publik. Jakarta: STIALAN

AG Subarsono. 2013. Evaluasi Kebijakan Publik: Konsep, Aplikasi, dan Teori. Yogyakarta: Pustaka Pelajar.
Boon Siong Neo, Geraldine Chen. 2007. Dynamic Governance: Embedding, Culture, Capabilities, and Change in Singapore. Singapore: 5 Toh Tuck Link. Habani Pasolong. 2013. Teori Administrsi Publik. Bandung: Afabeta.

Isal Mawardi. "Apa Sih Arti Program Layad

Rawat?".https://jabar.tribunn ews.com/2017/07/27/a pa-siharti-program-layad-rawatsimakpenjelasannya. pada tanggal 28 Juli 2019 pukul $11: 43$

Kasim, Azhar. 2015. Merekontruksi Indonesia: Sebuah Perjalanan Menuju Dynamic Governance. Jakarta: Buku Kompas

Riant Nugroho. 2014. Public Policy manajemen dinamika, analisis, konfergensi, dan kimia kebijakan. Jakarta: Elex Media Komputindo.

Wawan Dhewanto dkk. 2014. Management Inovasi: Peluang Sukses Menghadapi Perubahan. Yogyakarta: Andi offset. 